\title{
Anti-inflammatory Activity of Crude Extract and Fractions of Nectandra falcifolia Leaves
}

\author{
Juliana Oliveira de Melo, ${ }^{a}$ Maria da Conceição Torrado Truiti, ${ }^{b}$ Marcelo Nicolás Muscará, ${ }^{c}$ \\ Simone Marques BolonheIs, ${ }^{c}$ Jailson Araujo Dantas, ${ }^{a}$ Silvana Martins CAPARroz-Assef, ${ }^{a}$ \\ Roberto Kenji Nakamura CumAN, ${ }^{a}$ and Ciomar Aparecida BersANI-AMAdo*,a \\ ${ }^{a}$ Laboratory of Inflammation, Department of Pharmacy and Pharmacology, State University of Maringá-PR; ${ }^{b}$ Laboratory \\ of Pharmaceutical Technology, Department of Pharmacy and Pharmacology, State University of Maringá-PR; Brazil: and \\ ${ }^{c}$ Department of Pharmacology of the Institute of Biomedical Sciences, University of São Paulo-SP; Brazil. \\ Received May 18, 2006; accepted July 20, 2006
}

The present study evaluated the effect of the crude extract of the leaves of Nectandra falcifolia (NeEs) Castiglioni and its fractions in different experimental models of inflammation (paw edema, pleurisy, and ear edema). Carrageenan-induced edema of the paw and pleurisy were evaluated in Wistar rats (180-220 g), which were treated with different doses of the total extract $\left(250,500 \mathrm{mg} \cdot \mathrm{kg}^{-1}\right)$. Edema of the ear, induced by croton oil, and determination of myeloperoxidase activity were evaluated in Swiss mice $(25-35 \mathrm{~g})$. In this experiment, the crude extract of Nectandra falcifolia (Nf) $(1.25,2.5,5.0,7.5 \mathrm{mg})$ and the hexane, chloroform, ethyl-acetate and hydromethanol fractions $(5.0 \mathrm{mg})$ were applied topically, immediately after application of the oil. The crude extract of $\mathrm{Nf}\left(500 \mathrm{mg} \cdot \mathrm{kg}^{-1}\right)$ significantly reduced edema of the paw compared to the control group. Similarly, at doses of 250 and $500 \mathrm{mg} \cdot \mathrm{kg}^{-1}$ it significantly reduced the volume of pleural inflammatory exudate compared to the control animals. However, it did not change the number of migrated cells. At doses of 2.5, 5.0 and 7.5 mg, the crude extract significantly inhibited edema of the ear and the influx of neutrophils. The fractions from Nectandra falcifolia (hexane, chloroform, ethyl acetate and hydromethanol) also inhibited edema of the ear. Taken together, the results demonstrated that the crude extract and its fractions administered to animals orally or topically showed an anti-inflammatory effect.

Key words Nectandra falcifolia; anti-inflammatory; paw edema; pleurisy; ear edema

The family Lauraceae, to which the species Nectandra falcifolia belongs, contains some $2500-3000$ species in 49 genus. The family is widely distributed in the tropical and subtropical regions of the planet, predominantly in southeast Asia and in Brazil. ${ }^{1,2)}$

Some species of the generus Nectandra are used in folk medicine as an antifungal, antidiarrheal, analgesic and antirheumatic agents. Several investigations have demonstrated the biological activity of certain species, e.g., antitumor activity of Nectandra rigida, ${ }^{3)}$ antimalarial activity of Nectandra cuspidate $^{4)}$ and Nectandra salicifolia. ${ }^{5)}$ This last species also shows activity in cardiovascular diseases. ${ }^{6}$

Preliminary studies in our laboratory have shown that the crude extract of the leaves of Nectandra falcifolia reduces vascular permeability induced by phlogistic agents. ${ }^{7)}$ These data indicated, therefore, that the extract might have an antiinflammatory effect, and could be used in the development of new drugs for the treatment of inflammatory diseases.

Phytochemical studies have reported the presence of flavonoids and lignans in species of Nectandra. ${ }^{8-10)}$ Both these compounds have biological properties that can contribute to the anti-inflammatory effect of this plant. ${ }^{11,12)}$

Therefore, in the present study we investigated the effect of the crude extract of Nectandra falcifolia and its fractions on the inflammatory response, using different experimental models.

\section{MATERIALS AND METHODS}

Animals Male Wistar rats $(180-220 \mathrm{~g})$ and male Swiss mice $(25-35 \mathrm{~g})$ were used. The animals were maintained under controlled temperature of $22^{\circ} \mathrm{C}$ and a $12 \mathrm{~h} \mathrm{light/dark}$ cycle, with water and food ad libitum. The experimental protocol was approved by the Committee for Animal Ethics of the State University of Maringá (003/04-CEEA).

Plant Material Leaves of the plant Nectandra falcifolia were collected in March 2000, in the floodplain of the Upper Paraná River, Municipality of Taquaraçú, state of Mato Grosso de Sul. The material was appropriately preserved and deposited in the holdings of the Nupélia Herbarium at the University of Maringá-PR (HNUP $n^{\circ} 1421$ ).

Obtaining the Extract The plant material was dried in an air-circulating oven at $40^{\circ} \mathrm{C}$ and then ground in a cutting mill $(580 \mathrm{~g})$. The extract was obtained by extraction with absolute ethanol at room temperature. The solvent was then removed in a rotating evaporator, resulting in $64 \mathrm{~g}$ of ethanolic extract. $^{7)}$

Fractioning the Extract Part of the crude extract $(28 \mathrm{~g})$ was dissolved in $\mathrm{MeOH}: \mathrm{H}_{2} \mathrm{O}(1: 1)$ and extracted by liquid-liquid partitioning, with solvents of different polarities, resulting in the following fractions: hexane fraction (HF, $6.54 \mathrm{~g}$ ), chloroform fraction (CF, $3.88 \mathrm{~g}$ ), ethyl acetate fraction (AF, $3.91 \mathrm{~g})$ and hydromethanol fraction (MF, $12.62 \mathrm{~g}$ ).

Preparation of the Solutions For the trials with pleurisy and edema of the paw, the crude extract of Nectandra falcifolia $(\mathrm{Nf})$ was diluted in a solution of $16 \%$ dimethylsulfoxide (DMSO/water, $1: 6$ ), immediately prior to use.

For the trials with edema of the ear, the $\mathrm{Nf}$ crude extract and the methanol and ethyl acetate fractions were diluted in a solution of acetone/water $(1: 1)$. The hexane and chloroform fractions were diluted in a solution of chloroform/water $(7: 3)$.

Carrageenan Induced Rat Paw Edema Paw edema was induced by interdermal injection of $0.1 \mathrm{ml}$ of a suspen- 
sion of carrageenan dissolved in saline $(2.0 \mathrm{mg} / \mathrm{ml})$, in the left hind foot pad. As control, an equal volume of saline was injected into the opposite hind paw, according to the technique of Winter et al. ${ }^{13)}$ The volumes of the paw $(\mu 1)$ up to the tibiotarsal joint was measured 1,2 and $4 \mathrm{~h}$ after injection of the carrageenan, by means of a Ugo Basile $\left.{ }^{(}\right)$digital pletismograph. Edema was expressed in terms of the increase in the volume of the paw, subtracting the values of the paw injected with saline (control paw) from the values of the paw injected with carrageenan.

The Nf crude extract $\left(250,500 \mathrm{mg} \cdot \mathrm{kg}^{-1}\right)$, indomethacin $\left(5 \mathrm{mg} \cdot \mathrm{kg}^{-1}\right)$, the reference anti-inflammatory, and the vehicle $(16 \%$ DMSO) were administered orally by gavage in the animals, which had fasted for $15 \mathrm{~h}, 30 \mathrm{~min}$ prior to induction of the edema. One group of animals received an equivalent volume of $0.9 \%$ saline orally, under the same conditions as the previous groups.

Carrageenan Induced Pleurisy in Rats Pleurisy was induced by injection of $0.25 \mathrm{ml}$ of a carrageenan suspension $(200 \mu \mathrm{g})$ into the intrapleural cavity, in the region of the right mediastinum between the 3rd and 4th ribs, according to the technique described by Vinegar et al. ${ }^{14)}$ The carrageenan was diluted in saline buffered with phosphate (PBS, $\mathrm{pH}=7.4)$. At hour 4 after induction of the pleurisy, the animals were anesthetized and killed, to collect the intrapleural inflammatory exudate. The material, collected by aspiration, was transferred to conical centrifuge tubes. The total volume of the exudate was measured and a $50 \mu \mathrm{l}$ aliquot was used to determine the number of leukocytes in a Neubauer chamber. For the differential leukocyte count, the red blood cells were lysed by adding Turk's solution, and the resulting fluid was centrifuged at $2500 \mathrm{rpm}$ for $10 \mathrm{~min}$, and the cells were resuspended. The slides were prepared, dried, fixed, and colored. The number of mononuclear and polymorphonuclear leukocytes present in the exudate was determined by means of an ordinary light microscope.

The Nf crude extract $\left(250,500 \mathrm{mg} \cdot \mathrm{kg}^{-1}\right)$, indomethacin $\left(5 \mathrm{mg} \cdot \mathrm{kg}^{-1}\right)$, the vehicle $(16 \% \mathrm{DMSO})$ and the saline $(0.9 \%)$ were administered orally by gavage, in different groups of rats, which had fasted for $15 \mathrm{~h}, 30 \mathrm{~min}$ prior to the induction of pleurisy.

Determination of the Concentration of Total Nitrate $\left(\mathrm{NO}_{3}^{-}+\mathrm{NO}_{2}^{-}\right)$in the Pleural Exudates The concentration of total nitrate, an indicator of NO synthesis, was determined in the pleural exudates. ${ }^{15}$ ) The samples were deproteinized by centrifugation $\left(5000 \mathrm{~g}\right.$ for $120 \mathrm{~min}$ at $4{ }^{\circ} \mathrm{C}$ ) in eppendorf tubes with $10 \mathrm{kDa}$ filters. Total nitrate was determined by first incubating the samples and calculating the standard curve (aqueous solutions of $\mathrm{KNO}_{3}$ in concentrations from 0.2 to $200 \mu \mathrm{M})$ with $20 \mu \mathrm{l}$ NADPH $(100 \mu \mathrm{M})$, FAD $(5 \mu \mathrm{M})$ and $\mathrm{NO}_{3}{ }^{-}$reductase $(200 \mu \mathrm{m} / \mathrm{ml})$ for $1 \mathrm{~h}$ at $37^{\circ} \mathrm{C}$. Next, $20 \mu \mathrm{l}$ LDH $(13.5 \mathrm{U} / \mathrm{ml})$ and pyruvate $(9 \mathrm{~mm})$ was added, and the samples were further incubated for $30 \mathrm{~min}$ at $37^{\circ} \mathrm{C}$. After this period, $50 \mu \mathrm{l}$ of Griess reagent (a solution containing $0.1 \%$ sulfanilamide $+0.01 \%$ naphthylethylenediamine in $5 \%$ phosphoric acid) was added, and the samples allowed to rest for $10 \mathrm{~min}$ in ambient temperature. The concentrations of total nitrate were determined in the exudate by measuring the absorbancy $(540 \mathrm{~nm})$ with a Spectra Max Plus reader.

Croton oil Induced Ear Edema in Mouse The edema was induced by application of $20 \mu \mathrm{l}$ of croton oil $(200 \mu \mathrm{g}) \mathrm{di}-$ luted in a solution of acetone/water $(7: 3)$ to the inner surface of the mouse's left ear. The right ear received only the vehicle $(20 \mu 1) .{ }^{16)}$ Immediately after injecting the phlogistic agent, in the groups of treated animals we applied $20 \mu \mathrm{l}$ of the total extract $(1.25,2.5,5.0,7.5 \mathrm{mg})$ or of the fractions $(5.0 \mathrm{mg})$ to the left ear. In the control group, $20 \mu \mathrm{l}$ of the vehicle was applied to the left ear. After $6 \mathrm{~h}$, the animals were killed, and the ears were sectioned in discs $6.0 \mathrm{~mm}$ in diameter and weighed (mg) in an analytical balance. The percentage of inhibition of edema was determined.

Activity of Myeloperoxidase (MPO) The MPO activity was evaluated in the supernatant of homogenates of the ear sections (controls and those treated with crude extract, $5.0 \mathrm{mg}$; or indomethacin, $1.0 \mathrm{mg}$ ), according to the technique described by Bradley et al. ${ }^{17)}$ The ear tissue was placed in $50 \mathrm{~mm}$ potassium phosphate buffer, $\mathrm{pH} 6.0$, containing $0.5 \%$ hexadeciltrimethylammonium bromide (Sigma, $1 \mathrm{ml} / 50 \mathrm{mg}$ of tissue) in a Potter homogenizer. The homogenate was vortex-mixed and centrifuged for $5.0 \mathrm{~min}$ at $2500 \mathrm{rpm}$. Ten microliters of the supernatant thus obtained was added to a 96well microplate, in triplicate, followed by addition of $200 \mu \mathrm{l}$ of a buffer solution containing $O$-dianisidine dihydrochloride (Sigma, $16.7 \mathrm{mg})$, bidistilled water $(90 \mathrm{ml})$, potassium phosphate buffer $(10 \mathrm{ml})$ and $1 \% \mathrm{H}_{2} \mathrm{O}_{2}(50 \mu \mathrm{l})$. The enzyme activity was determined by measuring the absorbancy $(460 \mathrm{~nm})$ with a Spectra Max Plus reader, and recorded at 15.0-s intervals for $2.0 \mathrm{~min}$.

Statistical Analysis The results are presented as mean \pm standard error of the mean (S.E.M.). The data were submitted to analysis of variance (ANOVA), followed by Tukey's test. $p<0.05$ was considered as the significance level.

\section{RESULTS}

Effect of the Crude Extract of Nectandra falcifolia on Edema of the Paw Intradermal injection of carrageenan into one of the hind paw of normal rats (control grouptreated orally with saline or DMSO) caused a local inflammatory response, which reached a maximum intensity of edema at hour 4 after application of the phlogistic agent.

The crude extract of Nectandra falcifolia, at a dose of $250 \mathrm{mg} \cdot \mathrm{kg}^{-1}$, did not alter the development of edema of the foot compared to the control group. However, at a dose of $500 \mathrm{mg} \cdot \mathrm{kg}^{-1}$ it caused a statistically significant reduction in the intensity of response, at hours 2 and 4 after injection of the carrageenan. Treatment of the animals with indomethacin, the reference anti-inflammatory, significantly reduced the intensity of edema in all the periods evaluated. The results are presented in Fig. 1.

Effect of the Crude Extract of Nectandra falcifolia on Pleurisy Intrapleural injection of carrageenan in groups of animals pre-treated orally with saline or DMSO, induced an acute inflammatory response, characterized by an increase in the volume of the pleural exudate and the number of leukocytes migrated to the cavity, compared to the base parameters (obtained from normal animals which received an injection of PBS in the cavity). Treatment of the animals with the Nf crude extract reduced the volume of the inflammatory pleural exudate; however, it did not alter the number of migrated cells. As previously observed, the doses of 250 and 500 $\mathrm{mg} \cdot \mathrm{kg}^{-1}$ similarly reduced the intensity of the response. 


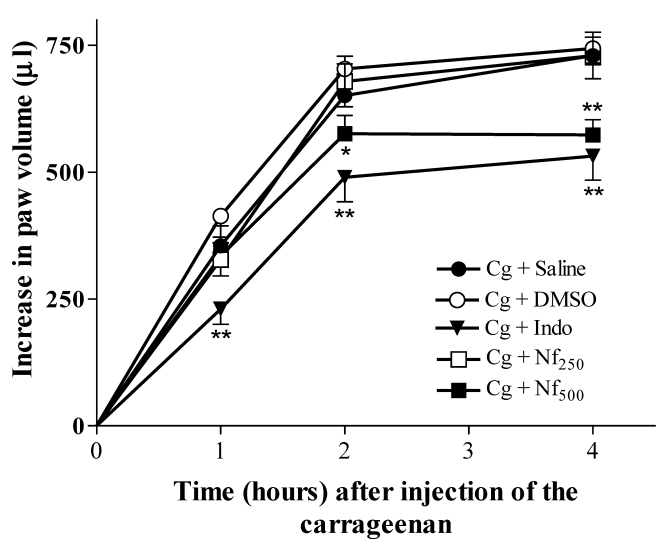

Fig. 1. Effect of the Crude Extract of Nectandra falcifolia (Nf) on the Development of Edema Induced by Intraplantar Injection of Carrageenan $(\mathrm{Cg})$ in Male Wistar Rats (180-220 g)

The animals ( $n=8$ in each group), were treated orally with the Nf crude extract, in the indicated concentrations, $30 \mathrm{~min}$ prior to the injection of carrageenan $(200 \mu \mathrm{g})$. Indomethacin (Indo), administered orally at $5 \mathrm{mg} \cdot \mathrm{kg}^{-1}$, was used as the reference antiinflammatory (positive control). Each point represents the mean volume of the paw \pm S.E.M., at 1,2 and $4 \mathrm{~h}$ after injection of the carrageenan. $* p<0.05 ; * * p<0.01$, compared to the control groups, treated with saline and DMSO (ANOVA, Tukey's test).

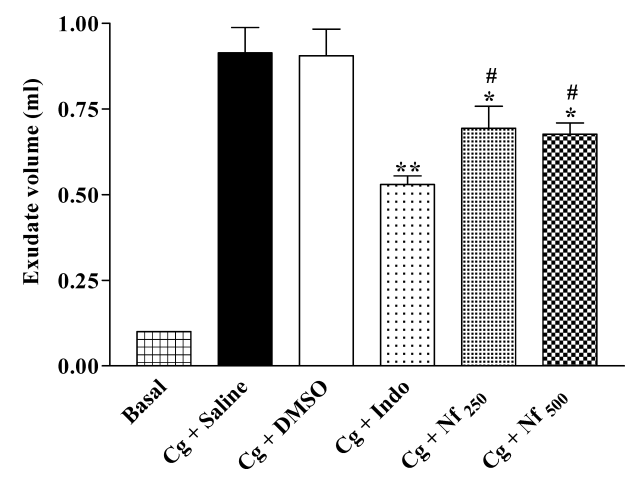

Fig. 2. Effect of the Crude Extract of Nectandra falcifolia (Nf) on Pleurisy Induced by Intrapleural Injection of Carrageenan $(\mathrm{Cg})$ in Male Wistar Rats $(180-220 \mathrm{~g})$

The animals ( $n=8$ for each group), were treated orally with the $\mathrm{Nf}$ crude extract, at the concentrations indicated, $30 \mathrm{~min}$ prior to the injection of carrageenan $(200 \mu \mathrm{g})$. Indomethacin (Indo), administered orally at $5 \mathrm{mg} \cdot \mathrm{kg}^{-1}$, was used as the reference anti-inflammatory (positive control). One group of animals received an intrapleural injection of saline (basal). Each point represents the mean volume of the pleural exudate \pm S.E.M., $4 \mathrm{~h}$ after injection of carrageenan. $* p<0.01, * * p<0.001$, compared to the control groups $(\mathrm{Cg}+$ saline), $\# p<0.05$, compared to the Indo group (ANOVA, Tukey's test).

Treatment of the animals with indomethacin caused a pronounced reduction in the volume of the exudate. The results are presented in Fig. 2 and Table 1.

Effect of the Crude Extract of Nectandra falcifolia on the Concentration of Total Nitrate Present in the Pleural Exudates The levels of NO were significantly increased in the exudate from rats pretreated with saline $(\mathrm{Cg}+$ saline $)$ or $16 \%$ dimethylsulfoxide ( $\mathrm{Cg}+\mathrm{DMSO})$, which received an intrapleural injection of carrageenan, compared to the basal group (normal animals which received an injection of PBS in the pleural cavity). Treatment of the animals with the Nf crude extract did not change the concentration of nitrate in the inflammatory pleural exudate. The results are shown in Fig. 3.

Effect of the Crude Extract and the Fractions from Nectandra falcifolia on Edema of the Ear Application of croton oil to the left ear of the mice induced a very evident
Table 1. Number of Total and Differential Leukocytes in the Pleural Inflammatory Exudate of the Rats

\begin{tabular}{lccc}
\hline \hline \multirow{3}{*}{$\begin{array}{c}\text { Groups of } \\
\text { animals }\end{array}$} & Cells $/ \mathrm{mm}^{3}$ \\
\cline { 2 - 4 } & Total leukocytes & $\begin{array}{c}\text { Mononuclears } \\
\text { leukocytes }\end{array}$ & $\begin{array}{c}\text { Polymorphonuclears } \\
\text { leukocytes }\end{array}$ \\
\hline Basal & $6700 \pm 450$ & $1800 \pm 160$ & $4900 \pm 390$ \\
$\mathrm{Cg}+$ Saline & $59800 \pm 4810^{*}$ & $13440 \pm 1753^{*}$ & $46360 \pm 4271^{*}$ \\
$\mathrm{Cg}+\mathrm{DMSO}$ & $60270 \pm 3910^{*}$ & $9850 \pm 1336^{*}$ & $50420 \pm 2999^{*}$ \\
$\mathrm{Cg}+\mathrm{Indo}$ & $63170 \pm 4206^{*}$ & $12670 \pm 687^{*}$ & $49390 \pm 3626^{*}$ \\
$\mathrm{Cg}+\mathrm{Nf}_{250}$ & $58630 \pm 6937^{*}$ & $8148 \pm 776^{*}$ & $49200 \pm 5390^{*}$ \\
$\mathrm{Cg}+\mathrm{Nf}_{500}$ & $58110 \pm 3727^{*}$ & $8323 \pm 883^{*}$ & $50000 \pm 3781^{*}$ \\
\hline
\end{tabular}

Each value represents the mean number of leukocytes \pm S.E.M. counted in the pleural inflammatory exudate of the animals ( $n=8$ for each group), $4 \mathrm{~h}$ after injection of carrageenan $(\mathrm{Cg}, 200 \mu \mathrm{g})$, Indomethacin (Indo), administered orally at $5 \mathrm{mg} \cdot \mathrm{kg}^{-1}$, was used as the reference anti-inflammatory (positive control). One group of animals received an intrapleural injection of saline (basal). $\mathrm{Nf}=$ Nectandra falcifolia,$* p<0.001$, compared to the basal group (ANOVA, Tukey's test).

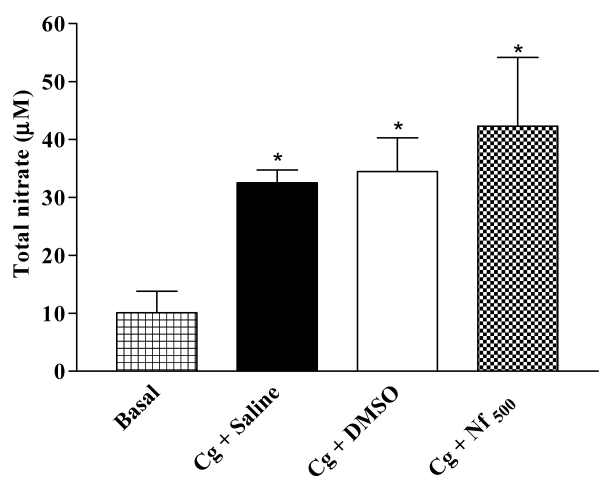

Fig. 3. Effect of the Crude Extract of Nectandra falcifolia $(\mathrm{Nf})$ on the Concentration of Nitrate in the Pleural Inflammatory Exudate of Male Wistar Rats $(180-220 \mathrm{~g})$

The animals ( $n=8$ in each group) were treated orally with saline, DMSO or Nf crude extract, in the indicated concentration, $30 \mathrm{~min}$ prior to the injection of carrageenan $(\mathrm{Cg}$, $200 \mu \mathrm{g}$ ). One group of animals received an intrapleural injection of saline (basal). Each point represents the mean of the concentration of nitrate \pm S.E.M. $* p<0.001$, compared to the basal group (ANOVA, Tukey's test).

inflammatory response by hour 6 . The weight of the ear doubled compared to the right ear (basal, with no croton oil applied). The crude extract of Nectandra falcifolia failed to inhibit the intensity of edema at a dose of $1.25 \mathrm{mg}$; however, at doses of $2.5,5.0$, and $7.5 \mathrm{mg}$ this extract significantly reduced the intensity of edema (Fig. 4). Additionally, application of the hexane, chloroform, ethyl-acetate and hydromethanol fractions at a dose of $5.0 \mathrm{mg}$ also significantly reduced the edema of the ear; this effect was similar for all four fractions tested (Table 2). Treatment with indomethacin, the positive control, caused an accentuated inhibition of the inflammatory response which differed significantly from the other treatments (crude extract and fractions).

Effect of the Crude Extract of Nectandra falcifolia on the Activity of Myeloperoxidase (MPO) MPO is an enzyme present in the intracellular granules of neutrophils, and can be used as a marker for the influx of polymorphonuclear leukocytes into inflammed tissues. Application of croton oil induced an increase in MPO activity on the order of 20-fold, at hour 6 after application of the stimulus. The $\mathrm{Nf}$ crude extract $(5.0 \mathrm{mg})$ and indomethacin $(1.0 \mathrm{mg})$ significantly inhibited the activity of the enzyme. These results are presented in Fig. 5. 


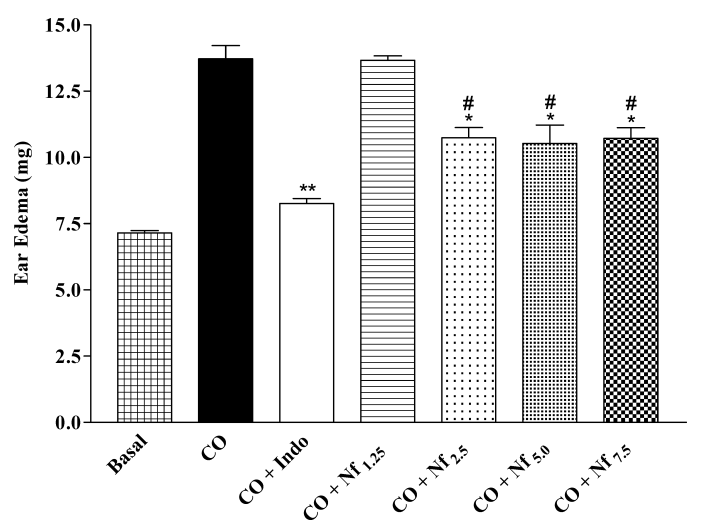

Fig. 4. Effect of the Crude Extract of Nectandra falcifolia (Nf) on Edema of the Ear Induced by Croton Oil (CO) in Male Swiss Mice $(25-35 \mathrm{~g}$ )

The animals ( $n=8$ for each group) were treated topically with the Nf crude extract, at the indicated concentrations, immediately after application of croton oil $(200 \mu \mathrm{g})$ to the left ear. Indomethacin (Indo), $1 \mathrm{mg}$ of which was administered topically, was used as the reference anti-inflammatory (positive control). Ears which received only an application of the vehicle (basal). Each column represents the mean weight of the ears \pm S.E.M., $6 \mathrm{~h}$ after application of the croton oil. $* p<0.01$, $* * p<0.001$, compared to the control group (CO), $\# p<0.05$, compared to the Indo group (ANOVA, Tukey's test).

Table 2. Percentage (\%) of Inhibition of Ear Edema Induced by Croton Oil $(200 \mu \mathrm{g})$

\begin{tabular}{lcc}
\hline \hline Groups & Dose (mg/ear) & Inhibition (\%) \\
\hline CO & - & - \\
CO+Indo & 1.0 & 83.3 \\
CO+HF & 5.0 & 53.0 \\
CO+CF & 5.0 & 65.1 \\
CO+AF & 5.0 & 59.1 \\
CO+MF & 5.0 & 65.1 \\
\hline
\end{tabular}

Croton oil (CO), Indomethacin (Indo), hexane fraction (HF), chloroform fraction (CF), ethyl-acetate fraction (AF), hydromethanol fraction (MF).

\section{DISCUSSION}

The data from this study indicated that the plant species Nectandra falcifolia (Nf) shows anti-inflammatory activity in several experimental models of inflammation (paw edema and pleurisy induced by carrageenan, and edema of the ear induced by croton oil). However, the inhibitory effects caused by the extract on the models studied were different.

In the pleurisy model, the $\mathrm{Nf}$ crude extract administered orally caused significant inhibition only of fluid extravasation, and did not alter leukocyte migration. However, in the ear edema model, the extract applied topically inhibited both fluid extravasation and the cellular influx, as indicated by a reduction in myeloperoxidase activity. This enzyme, found in the azurophilic granules of neutrophils and other cells of myeloid origin, is commonly used as a marker for the influx of polymorphonuclear leukocytes into the area of the le$\operatorname{sion}^{18,19)}$ and its inhibition indicates an anti-inflammatory action. ${ }^{20)}$ This difference may be related to several factors, including the action of the extract on the different inflammatory mediators involved in the models studied.

It is well known that different mechanisms may be involved in the genesis of inflammatory reactions. The development of the inflammatory response induced by carrageenan (paw edema and pleurisy) is characterized by an initial stage $(1-2 \mathrm{~h})$ which is dependent on the release of

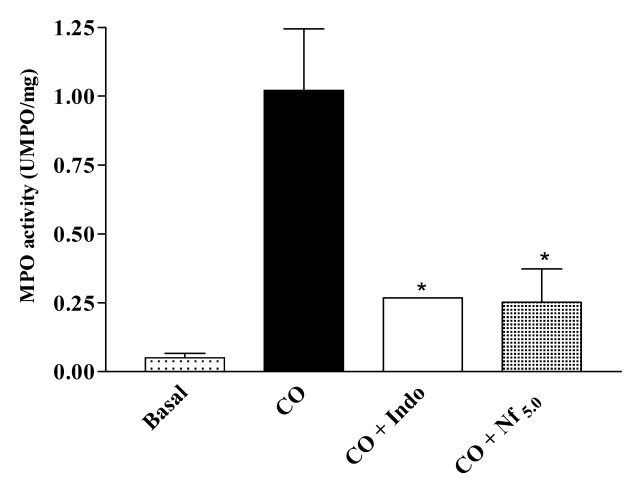

Fig. 5. Effect of the Crude Extract of Nectandra falcifolia (Nf) on MPO Activity in Ear Tissue from Male Swiss Mice (25-35 g)

The animals ( $n=8$ for each group) were treated topically with the $\mathrm{Nf}$ crude extract, at the indicated concentration, immediately after application of $200 \mu \mathrm{g}$ of croton oil (CO) to the left ear. Indomethacin (Indo), $1 \mathrm{mg}$ of which was administered topically, was used as the reference anti-inflammatory (positive control). Ears which received only an application of the vehicle (Basal). Each column represents the MPO-mediated activity \pm S.E.M., $6 \mathrm{~h}$ after application of the croton oil. $* p<0.001$, compared to the control group (CO). (ANOVA, Tukey's test).

histamine, serotonin and bradykinin, followed by a later stage $(3-4 \mathrm{~h})$ which is maintained principally by the release of prostanoids. ${ }^{21,22)}$ It has also been shown that nitric oxide (NO) has an important role as much as in the regulation of vascular permeability as in cell migration induced by pro-inflammatory agents, including carrageenan. ${ }^{18,23-25)}$ Studies by Banerjee et al. ${ }^{26)}$ and Saleh et al. ${ }^{18)}$ have shown that NO appears to play an important role in modulating the generation of prostaglandins at the inflammation site. On the other hand, the edema of the ear induced by local application of croton oil involves the activation of phospholipase $\mathrm{A}_{2}$ and, consequently, biosynthesis of prostaglandins and leucotriens. ${ }^{27,28)}$

From the data of this study, we cannot conclude clearly which pro-inflammatory mediator of agent is inhibited by the extract. Particularly in the pleurisy model utilized, although the extract did not reduce the concentration of total nitrate in the pleural exudates, we cannot discard the possibility that this mediator participates in the inflammatory response.

Moreover, it is important to emphasize that the release of inflammatory mediators is probably unrelated not only to the type of phlogistic agent used to induce the reaction, but also to the tissue affected. As observed in our study, the $\mathrm{Nf}$ crude extract, when administered to the animals in low concentrations, reduced the fluid extravasation only in the pleurisy model, but not in the model of edema of the paw.

Taken together, these results corroborate the data of other investigators who observed differences in the action of plant extracts or even of traditional anti-inflammatory on the inflammatory stages and the mediators, in different experimental models ${ }^{18,29)}$

Additionally, as shown in the present study, the hexane, chloroform, ethyl-acetate and hydromethanol fractions obtained from the Nf crude extract also showed an anti-inflammatory effect on edema of the ear. Thus, it is possible that the active constituents present in the plant extract could inhibit the different stages of the inflammatory reaction.

It is also important to consider differences in the process of absorption of the extract, related to the routes of administration used (oral and topical). In this context, we cannot discard the possibility of irregular absorption after oral administration. Although there is still no detailed published informa- 
tion on the process of gastrointestinal absorption of the different chemical constituents present in plants, some investigations have indicated that, the absorption process can be influenced by the chemical structure of the substance. ${ }^{30)}$

In summary, the present study provided evidence indicating that the $\mathrm{Nf}$ crude extract and its fractions showed significant anti-inflammatory activity when administered orally or topically to animals. These data support the development of additional studies in order to identify the active constituents of the extract of Nectandra falcifolia and to elucidate its true mechanism of action.

Acknowledgements We gratefully acknowledge financial support received from the Coordenação de Aperfeiçoamento de Pessoal de Nível Superior (CAPES). We also thank Mrs. Célia Regina Miranda for technical assistance.

\section{REFERENCES}

1) Cronquist A., "An Integrated System of Classification of Flowering Plants," Columbia University, New York, 1962, p. 1981.

2) van der Werff H., Richter H. G., Ann. Mo. Bot. Gard., 8, 419-432 (1996).

3) Le Quesne P. W., Larrahondo J. E., Raffauf R. F., J. Nat. Prod., 43, 353-359 (1980).

4) Muñoz V., Sauvain M., Bourdy G., Callapa J., Bergeron S., Roj I., Bravo J. A., Balderrama L., Ortiz B., Gimenez A., Deharo E., J. Ethnopharmacol., 69, 127-137 (2000).

5) Bohlke M., Guinaudeau H., Angerhofer C. K., Wongpanich V., Soerjato D. D., Farnsworth N. R., J. Nat. Prod., 59, 576-580 (1996).

6) Slish D. F., Ueda H., Arvigo R., Balick M. J., J. Ethnopharmacol., 66, 159-165 (1999).

7) Truiti M. C. T., Chemical study and evaluation of biological activities of naturally occurring species in the Brazilian stretch of the Upper Paraná River. Ph. D Thesis, State University of Maringá, Maringá, Pr. Brazil, 2004.

8) Barbosa-Filho J. M., Yoshida M., Gottlieb O. R., Phytochemistry, 28, 1991 (1989).

9) Moro J. C., Fernandes J. B., Vieira P. C., Yoshida M., Gottlieb O. R.,
Gottlieb H. E., Phytochemistry, 38, 267-270 (1987).

10) Ribeiro A. B., Silva D. H. S., Bolzani V. S., Eclet. Quím., 27, 35-44 (2002).

11) Cho J. Y., Baik K. U., Yoo E. S., Yoshikawa K., Park M. H., J. Nat Prod. Nat., 63, 1205-1209 (2000).

12) Williams C. N., Honet J. R. S., Harbone J. B., Greenham J., Eeagles J., Phytochemistry, 38, 267-270 (1995).

13) Winter C. A., Risley E. A., Nuss G. V., Proc. Soc. Exp. Biol. Med., 111, 544-547 (1962).

14) Vinegar R., Truax J. F., Selph J. L., Proc. Soc. Exp. Biol. Med., 143, $711-714$ (1973).

15) Grisham M. B., Johnson G. G., Lancaster J. R., Jr., Methods Enzymol., 268, 237-246 (1996).

16) Van Arman G. C., Clin. Pharm. Ther, 16, 900-904 (1974).

17) Bradley P. P., Priebat D. A., Chiristensen R. D., Rothstein G., J. Invest. Dermatol., 78, 206-209 (1982).

18) Saleh T. S. F., Calixto J. B., Medeiros Y. S., Peptides, 20, 949—956 (1999).

19) Rao T. S., Currie J. L., Shaffer A. F., Isakson P. C., Inflammation, 17, 723-741 (1993).

20) Ajuebor M. N., Singh A., Wallace J. L., Am. J. Physiol. Gastrointest. Liver Physiol., 279, 238-244 (2000).

21) Tracey W. R., Nakane M., Kuk J., Budzik G., Klinghofer V., Harris R. Carter G., J. Pharmacol. Exp. Ther, 273, 1295-1299 (1995).

22) Di Rosa M., Willoughby D. A., J. Pharm. Pharmacol., 23, 297-298 (1971).

23) Rimele T. J., Sturn R. J., Adams L. M., Henry D. E., Heaslip R. J., Weichman B. M., Grimes D., J. Pharmacol. Exp. Ther, 245, 102-111 (1988).

24) Sautebin L., Ialemti A., Ianaro A., Di Rosa M., Biochem. Pharmacol., 55, 1113-1117 (1998).

25) Ferreira A. F., Role of endogenous nitric oxide in models of spontaneously hypertensive and normotensive rat pleurisy. M.Sc. Thesis, State University of Maringá, Maringá, PR., Brazil, 2004.

26) Banerjee T., Van der Vliet A., Ziboh V. A., Prostaglandins Leukot. Essent. Fatty Acids, 66, 485- 492 (2002).

27) Kondoh H., Sato Y., Kanoh H., J. Inv. Dermatol., 85, 64-69 (1985).

28) Furstenberger G., Marks F., Biochem. Biophys. Res. Commun., 92, 749-756 (1980).

29) Rotelli A. E., Guardia T., Juárez A. O., De La Rocha N. E., Pelzer L. E., Pharmacol. Res., 48, 601-606 (2003).

30) Di Carlo G., Mascolo N., Izzo A. A., Capasso F., Life Sci., 65, 337353 (1999). 